\title{
Influence of Type 2 Diabetes and the Sex on the Occurrence of Sub-Clinic Left-Ventricular Diastolic Dysfunction of the Heart
}

\author{
Ylber Jani' ${ }^{1}$, Verka Spiroska ${ }^{2}$
}

${ }^{1}$ PHO "Heart Diagnostic", Debar, Republic of Macedonia; ${ }^{2}$ University Clinic of Cardiology, Faculty of Medicine, University "Ss Cyril and Methodius“, Skopje, Republic of Macedonia

Citation: Jani Y, Spiroska V. Influence of Type 2 Occurrence of SubDysfunction of the 20ct15;5(3):302-312 http://dx.doi.org/10.3889/MJMS.1957. 5773.2012.0253.

Keywords: type 2diabetes; diabetic cardiomiopathy; subclinicl diastolic dysfunction; Doppler echocardiographanalysis; sex

Correspondence: Ylber Jani, MD, MSc. PHO"Heart Diagnostic", Debar, Republic of Macedonia. E-mail: ylber_jani@hotmail.com

Received: 20-May-2012; Revised: 05-Jun-2012; Accepted: 22-Jul-2012; Online first: 29-Aug-2012

Copyright: $\odot 2012$ Jani Y. This is an open-access article distributed under the terms of the Creative Commons Attribution License, which permits unrestricted use, distribution, and reproduction in any medium, provided the original author and source are credited.

Competing Interests: The author have declared that no competing interests exist.

Abbreviations: AGE-Age; BW-Body weight; $\mathrm{BH}$ -Bodyheight;BMI-Bodymassindex; SBP-Systolic blood pressure; DBP - Diastolic blood pressure; GLIK-Glycaemia; KRE-Creatinemia; TOT-cholTotal cholesterol; LDL-chol-Lowdensity cholesterol; Total cholesterol; LDL-chol-Lowdensity cholestero HDL-chol- High density cholesterol; TRI Triglyceride; LA - Left atrium; LAI - Left atrium index; AO-Aorta; LVEDD - Left ventricular end diastolic dimension; LVESD - Left ventricular end systolic dimension; PWLV-Posterior wall of left ventricular; IVS-Inter Ventricular septum; EF-Ejection fraction of the leftventricular; FS-Fraction of the shortening oftheleftventricus of helefverion E-Wave, IVR-t-is Left ventricular mass; LVMI- Left ventricular mas index.

\section{Abstract}

Aims: To test the hypothesis that: the potential of type 2 diabetes, in precipitation of the sub clinical left ventricular diastolic dysfunction at the female sex, in absence of high blood pressure disease, coronary disease and other known heart disease, is different in comparison to the male sex.

Material and Methods: Prospectively, 180 people with type 2 diabetes were tested, at the ages between 45 and 55, divided into 2 groups: 1) Control group- was comprised of 60 patients (30 male and 30 female), without diabetes, with similar epidemiological-demographic characteristics; 2) Diabetes group - was comprised of 120 patients (60 women and 60 men) with type 2 diabetes. The estimation of the diastolic function of the left ventricular was made by Doppler echocardiograph analysis of the diastolic time intervals, as well as analysis of the model of ventricular filling, shown with a transmitral flow-velocity profile, acquired with a conventional pulsed-wave Doppler.

Results: Significant changes between the groups in clinical variables were observed regarding body mass index, low density cholesterol and triglycerides, the variables gotten with the pulsed-wave Doppler of the transmitral flow, and the duration of the isovolumetric relaxation time.

Conclusions: In this study, we do not prove the hypothesis that the type 2 diabetes potential in the precipitation of the sub clinical left ventricular diastolic dysfunction at the female sex, in absence of coronary disease, blood pressure disease and other well known heart diseases, is different in comparison to the male sex.

\section{Introduction}

Sugar disease (Diabetes mellitus) is responsible for a wide spectrum of cardiovascular diseases. It is a risk factor for the development of heart failure [1]. In the last decade an increase of prevalence of type 2 diabetes has been noted, and with it cardiovascular complications [2]. In many epidemiological, clinical and experimental studies 
the assotiation between diabetes and left ventricular diastolic dysfunction has been proven [2].

The left ventricular diastolic dysfunction is a basic characteristic of diabetic heart disease (diabetic cardiomyopathy), defined as a disease of the myocardium at the sick with diabetes, in absence of coronary disease, blood pressure disease and other well known heart diseases [3], while diastolic dysfunction can be the first stage of diabetic cardiomyopathy, previously belonging to the systolic damages [4,5], and the diastolic abnormalities at these can bring higher morbidity and mortality [1]. The subclinical left ventricular diastolic dysfunction is proven at the people sick with type 2 diabetes with Dopplerechocardiography and in absence of coronary artery disease and ventricular hypertrophy. Result up until now from the experimental, pathological, epidemiological and clinical studies have shown that sugar disease brings functional and structural changes in the heart regardless of coronary artery disease, high blood pressure disease and other well known heart diseases, and maybe also on the difference in the sexes at the people sick with diabetes [1-5].

The subclinical left ventricular diastolic dysfunction is proven at the people sick with type 2 diabetes with Doppler-echocardiography and in absence of coronary disease, high blood pressure disease and other well known heart diseases, but the distribution still remains unclear. According to many characteristics, cardiovascular diseases are similar between the male and female sexes. But, recently, individual studies show significant differences at a wider specter of cardiovascular incidence. Prevalence of type 2 diabetes in the last two decades is increasing fast at the female sex in comparison to the male sex, and with the, the complications of diabetes. Prevalence of diastolic heart failure is greater at the female sex with type 2 diabetes in comparison to the male sex with type 2 diabetes. Women with type 2 diabetes have a higher risk of death from cardiovascular diseases in comparison to men with type 2 diabetes. Independently from the influence of diabetes in cardiovascular morbidity and mortality, the influence of diabetes and diabetes-sex interaction, in the distribution of subclinical left ventricular diastolic dysfunction at the people sick with type 2 diabetes and in absence of coronary disease, high blood pressure disease and other well known heart diseases, they are not clearly defined and the data is controversial [2, 59, 61-68].

The aims of this study are: 1) Evaluation of the distribution of the subclinical (asymptomatic) left ventricular diastolic dysfunction at the people sick with type 2 diabetes in absence of coronary disease, high blood pressure disease and other well known heart diseases; 2) Evaluation of the influence of the sex; 3) Evaluation of the influence and duration of diabetes with hypothesis that the potential for type 2 diabetes in the precipitation of the subclinical (asymptomatic) left ventricular diastolic dysfunction at women in absence coronary disease, high blood pressure disease and other well known heart diseases is different in comparison to men.

\section{Material and Methods}

Prospectively tested were 180 sick with type 2 diabetes and the age between 45 and 55, dividing into 2 groups. GROUP 1 (the control group): was comprised of 60 patients ( 30 women and 30 men) without diabetes with similar epidemiological-demographic characteristics. GROUP 2 (the tested group): was comprised of 120 patients (60 women and 60 men) with type 2 diabetes.

\section{Criteria for inclusion}

All patients that participated in this study were informed in detail and were asked to provide written accordance for their voluntary participation in the study. In the study, all sick with type 2 diabetes were included between the ages of 45 and 55 , diagnosed in accordance with the criteria of the American Diabetes Association: (if the fasting glycose is $>7.0 \mathrm{mmol} / \mathrm{L}$; the level of glycemia in the blood $>11 \mathrm{mmol} / \mathrm{L}-2$ hours after the glycose tolerant test);(72); and the sick that were treated with oral antidiabetics.

\section{Criteria for exclusion}

From the test excluded were: the sick from type 1 diabetes; the sick that take therapy with insulin; the sick with heart problems acquired or from birth, cardiomiopathies (primary and secondary), heart arrhythmias, atriumventricular block of 2-3 degree, the sick with changes in the electrocardiogram, the sick with implanted pacemaker, the sick with is-schemica heart disease, the sick with ventricular hypertrophy, the sick with high blood pressure, the sick with acute and chronic pneumonias, the sick with kidney insufficiency, age under 45 and over 55, the sick with hormonal therapy (estrogen/progesterone) and those sick with difficulties for acquiring an echographic window.

\section{Clinical evaluation}

Detailed anamnesis data were taken from each patient and a physical examination was completed. The clinical data include: -age, sex, body weight and height, 
body mass index (BMI) calculated as the weight divided with the height squared, body surface area calculated with the Mosteller-BAS $(\mathrm{m} 2)=($ height $(\mathrm{cm}) \times$ weight $(\mathrm{kg}) / 36001 /$ 2 formula, the duration and way of treatment of diabetes, the medication (hipoglycemies) and the dose with which the patients are being treated.

At all participants in the study external electrocardiograms (ECG with lab version 3.0) were: Measuring ofblood pressure according to standard protocol [73]; - In the blood and urine samples the determined were the values of: glycemia, lipid status (Total cholesterol, LDL-chol, HDL-chol, triglycerides), urea, creatine, uric acid, electrolytes ( $\mathrm{Na}, \mathrm{K}, \mathrm{Ca}$ ), in the morning, after 12 hour starvation. The received samples were analyzed with a (Reflotron Roche analizator).

\section{Echocardiographic study}

An Echocardiographic study was made with an Acuson 128 XP echocardiograph (with a $2.5 \mathrm{Mz}$ frequency probe, with M-mode, D-dimensional, and Doppler pulsant and continuous). The echocardiographic test was done with the standard overview: the subject was lying on his left side. At all participants in the study a complete M-mode, D-dimensional, Doppler-echocardiographic study was done. The dimension of the left ventricle, atrium and the fat of the walls were measured from a bi-dimensional, targeted M-mode echocardiography, using the criteria of the American Association of echocardiography [74]. Measures were: the conventional parameters: - LVEDD - Left ventricular end diastolic dimension; LVESD - Left ventricular end systolic dimension; the dimensions of left atrium, aorta, the PWLV;-Posterior wall of left ventricular, and IVS - Intra-Ventricular septum; Ejection fraction of the left ventricle is determined by the formula: $\AA$ F =LVEDVLVESVILVEDVX100; - The dimensions of the left atrium $(\mathrm{LA} / \mathrm{cm})$; - The size of the left atrium is indexed for surface area(ILA/cm/m2): was calculated by the recommendations of the American and European association of echocardiography; The dilated left atrium is defined as ILA is $>2.4(\mathrm{~cm} / \mathrm{m} 2)$; - The left ventricular mass index (LVMI) is calculated according to the Deveraux formula [76]: (LVMI).gr=0.84 x ((1.04 x IVS + PWLV)-(LVESD))+0.6; The LVMI - Left ventricular mass index, is calculated by dividing: (LVM and BSA) (77). For hypertrophy, of the left ventricle, calculated was $L V M>134 \mathrm{~g} / \mathrm{m} 2$ for men and LVM $>110 \mathrm{~g} / \mathrm{m} 2$ for women.

The estimation ofDIASTOIC FUNCTION of the left ventriclewas donewith doppler-echocardiographicanalysis of the diastolic time intervals, as well as an analysis of the model of ventricular filling, represented by a transmitral flow-velocity profile, acquired with a conventional pulsedwave Doppler, where the sample volume is positioned between the peaks of the mitral leaflets, which enables registering of the maximal speed of the mitral flow. The size of the sample volume was $2-3 \mathrm{~mm}$. The analysis of the transmitral flow was done from an apical four-chamber view. The examination was done during normal expiration. The measurements were performed as middle values for 3 consecutive cycles, and the cycles in which a union of the $E$ and $A$ valve were turned off [75].

Doppler - the echocardiographic parameters of the mitral curve that are measured into two groups: - Peak velocity of early filling of E-wave; - Peak velocity of late filling of A-wave; - Relation between peak velocity of E and $A$ waves, or E/A;- Values of E/A relation; - Time of deceleration of $E$-wave on the diastole, as the time of the middle of the peak of the E-wave and the point where the basic line is extrapolated with the lower wing of the Ewave; - The time of isovolumenic relaxation as a time interval from the completion of the aorta flow until the beginning of the mitral flow.

Doppler-echocardiographic parametres that are used for estimation of the diastoic function, recommended by the European Group for Study of Diastoic Heart Failure [75]: 1) Normal diastolic function, if (E/A relation from 1.0 until 1.5; DT from 180 until $240 \mathrm{~m} / \mathrm{sec}$; time of isovolumen relaxation 74-90 $\mathrm{m} / \mathrm{sec}$ ); 2) Impaered relaxation, if $E<A$; $E / A<1.0 ; D T->240 \mathrm{~m} / \mathrm{sec}$; extended time of isovolumen relaxation $>90 \mathrm{~m} / \mathrm{sec}$. (Diastolic dysfunction of $1^{\text {st }}$ degree); 3) Impaered relaxation (pseudo-normalized pattern) if: the E/A relation is from 1.0 until 1.5; DT <180m/sec. (diastolic dysfunction of $2^{\text {nd }}$ degree); 4) I paered relaxation(restrictive pattern) if: E/A $>2.0$ and the time of deceleration $<180 \mathrm{~m} /$ sec. (diastolic dysfunction of $3^{\text {rd }}$ degree).

\section{Statistical analysis}

The acquired continuous data from the examinations for each group was shown as middle value +/-for standard deviation(SD). The statistical processing of data is done by the statical programs (STATISTICA 7.1 and SPSS 13.0).

\section{Results}

Clinical and with Doppler echocardiograph tested were 180 patients, of which 60 patients (30 men and 30 women) from the control group, and 120 patients (60 men and 60 women) with type 2 diabetes mellitus, in the tested group. 
Jani \& Spiroska. Type 2 Diabetes and the Sex on Sub-Clinic Left-Ventricular Diastolic Dysfunction

Baseline clinical and laboratory data are shown in Table 1.The majority of demographic and clinical data did not show significant differences among patients in different groups. Significant changes between the groups in the clinical variables were observed in relation to: The Body Mass Index (BMI).Patient from the type 2 diabetes group had significantly higher BMI $(27.764 .30)$ in relation to the $(25.92 \pm 2.85 ; 95 \% \mathrm{Cl}: 26.98-28.53 ; p<0.003)$, tested persons from the control group. Patient from the type 2 diabetes group, had significantly highervalues of LDL-chol and Trig. (LDL-chol $3.518 \pm 0.50$ in relation to $3.23 \pm 0.28$ $95 \% \mathrm{Cl} ; 3.09-3.24 ; \mathrm{p}<0.001)$; and Trig. $(2.16 \pm 0.24$ in relation to $2.02 \pm 0.13 ; 95 \% \mathrm{Cl}: 1.04-1.06 ; p<0.001 ;)$, in relation to the LDL-chol and Triglicerides in the control group.Patient from the type 2 diabetes group had significantly lowvalues of HDL-chol $(1.06 \pm 0.15$ in relation to $1.01 \pm 0.21 ; 95 \% \mathrm{Cl}: 1.04-1.06 ; p<0.008$ ), in relation to the HDL-chol. in the control group.

Table 1: Clinical and laboratory characteristics in each group.

\begin{tabular}{|c|c|c|c|}
\hline Variables & $\begin{array}{c}\begin{array}{c}\text { Control Group } \\
(n=60)\end{array} \\
\end{array}$ & $\begin{array}{c}\text { DM Group } \\
(n=120)\end{array}$ & $\mathrm{p}$ \\
\hline Age (yrs) & $50.22 \pm 3.46$ & $49.92 \pm 3.99$ & 0.385 \\
\hline BW (kg) & $72.37 \pm 10.48$ & $77.34 \pm 13.51$ & 0.013 \\
\hline $\mathrm{BH}(\mathrm{cm})$ & $168.63 \pm 6.45$ & $168.89 \pm 7.22$ & 0.878 \\
\hline $\mathrm{BMI}\left(\mathrm{kg} / \mathrm{m}^{2}\right)$ & $25.92 \pm 2.85$ & $27.76 \pm 4.30$ & 0.003 \\
\hline D.M.d (yrs) & & $3.00 \pm 1.30$ & \\
\hline $\mathrm{SBP}(\mathrm{mmHg})$ & $117.73 \pm 7.81$ & $115.66 \pm 7.87$ & 0.133 \\
\hline $\mathrm{DBP}(\mathrm{mmHg})$ & $79.50 \pm 2.29$ & $79.10 \pm 2.95$ & 0.492 \\
\hline Glic (mmol/l) & $5.40 \pm 0.80$ & $5.934 \pm 0.33$ & 0.381 \\
\hline Urea $(\mathrm{mmol} / \mathrm{l})$ & $6.97 \pm 0.40$ & $7.36 \pm 0.66$ & 0.133 \\
\hline Cre $(\mathrm{mmol} / \mathrm{l})$ & $78.45 \pm 14.33$ & $80.22 \pm 7.53$ & 0.820 \\
\hline Chol-tot ( $\mathrm{mmol} / \mathrm{l})$ & $5.85 \pm 0.44$ & $5.931 \pm 0.56$ & 0.220 \\
\hline LDLchol (mmol/l) & $3.23 \pm 0.28$ & $3.518 \pm 0.50$ & 0.000 \\
\hline HDL-chol (mmol/l) & $1.06 \pm 0.15$ & $1.01 \pm 0.21$ & 0.008 \\
\hline Trig $(\mathrm{mmol} / \mathrm{l})$ & $2.02 \pm 0.13$ & $2.16 \pm 0.24$ & 0.000 \\
\hline
\end{tabular}

Values are mean $\pm \mathrm{SD}$. $\mathrm{BW}=$ body weight; $\mathrm{BH}=$ body height; $\mathrm{BMI}=$ body mass index; $\mathrm{D} . \mathrm{M} . \mathrm{d}=$ diabetes mellitus duration; $\mathrm{SPB}=$ systolic blood pressure; $\mathrm{DPB}=$ diastolic blood pressure; $\mathrm{Glic}=$ glicemia; $\mathrm{Kre}=$ creatinin; $\mathrm{Chol}$-tot $=$ total holesterol; $\mathrm{LDL}$-chol = low density holesterol; HDL-chol = hight density holesterol; Trig = trigicerides.

Echocardiographic data, are shown in Table 2. There were not significant differences between the groups regarding:levt ventricle dimensions, levt ventricle ejection fraction,levt ventricle fractional shortening,thickness of interventricular septum,thicknessoflevtventricular posterior wall,levt atrium,aorta, indexed levt ventriculary mass, deceleration time of $E$-wave, and peak velocity of A-wave. Significant differences between the groups were observed in relation to the variables acquired with the pulsed-wave Doppler, on transmitral flow: Patient from the type 2 DM group, have a significantly lower peak velocity of E-wave $(0.66 \pm 0.17 \mathrm{~cm} / \mathrm{s})$ in relation to the control group $(0.73 \pm$ $0.16 \mathrm{~cm} / \mathrm{s}) ; p<0.01(p=0.004)$. Significant differences between the groups, were observed in relation to the distribution of $E / A<1.0$ relation. At the patient from the $D M$ group, the proportion of patients with $E / A<1.0$ is $37.50 \%$
Table 2: Basic echocardiographic variables of the tested groups.

\begin{tabular}{|c|c|c|c|}
\hline Variables & $\begin{array}{c}\text { Control Group } \\
(n=60)\end{array}$ & $\begin{array}{l}\text { DM Group } \\
(n=120)\end{array}$ & $\mathrm{p}$ \\
\hline LA (cm) & $3.28 \pm 0.45$ & $3.49 \pm 0.44$ & 0.004 \\
\hline ILA (cm/sf.t) & & $0.06 \pm 0.01$ & 0.234 \\
\hline & & $3.29=$ & 0.977 \\
\hline$(\mathrm{cm})$ & & & 0.820 \\
\hline & & 2.98 & 0.819 \\
\hline & & & 0.079 \\
\hline & & & 0.403 \\
\hline & & $0.6 \varepsilon$ & 0.731 \\
\hline & & 0.3 & 0.967 \\
\hline & 108 & 114.3 & 0.123 \\
\hline ILMVM $\left(\mathrm{gr} / \mathrm{m}^{2}\right)$ & & 60.4 & 0.733 \\
\hline & & & 0.004 \\
\hline & & & 0.354 \\
\hline $\mathrm{E} / \mathrm{A}(\mathrm{cm})$ & & & 0.020 \\
\hline & & $98.14 \pm 19.09$ & 0.0002 \\
\hline & $251.40 \pm 44.50$ & $249.62 \pm 54.02$ & 0.48 \\
\hline$E / A>1.0 n(\%)$ & 58 (96.7\%) & 75 (62.5\%) & NS \\
\hline$E / A<1.0 n(\%)$ & $2(3.3 \%)$ & $45(37.5 \%)$ & 0.001 \\
\hline
\end{tabular}

Values are mean $\pm S D$ or $n,(\%)$. LA = left atrium; ILA $=$ indexed left atrium; $A 0=$ aortae; ED- $d=$ end diastolic dimension of left ventricule; ES- $d$ = end systolic dimension of left ventricule; THPWthickening of posterior wall; $T H S=$ thickening of septum; $E F=$ ejection fraction; $F S=$ f raction 0 shortening; $L V M=$ levt ventricular mass; $I L V M=$ indexed levtventricular mass; $E=$ peac velosity of $\mathrm{E}$-wave; $\mathrm{A}=$ peac velosity of $\mathrm{A}$-wave; IVRT = isovolumetric relaksation time; $\mathrm{DC}-\mathrm{tE}=$ deceleration time ofE-wave.

(in 45 patients), in relation to $3.3 \%$ (in 2 patients), at the patient from the control group $(p<0.001)$. E/A<1.Ovalues, significantly differences at patient of the DM group (1.18 \pm $0.48)$, in relation to the patient from the control group (1.35 $\pm 0.31) ; p<0.05$ ( $p=0.02$ ). Significantly differences between the groups, were observed in relation to the duration of isovolumenic relaxation time. The patient from the DM group, for $(98.14 \pm 19.09 \mathrm{msec})$, in relation to the patient from the control group,for $(91.38 \pm 19.09 \mathrm{msec})$ and $\mathrm{p}<0.001$, have significantly longer duration of isovolumenic relaxation time.

Table 3: Analyzed clinical and laboratory characteristics in relation to SEX in diabetic group.

\begin{tabular}{|c|c|c|c|}
\hline \multirow{2}{*}{ Variables } & \multicolumn{2}{|c|}{ DM Group $(n=120)$} & \multirow[b]{2}{*}{ p-Value } \\
\hline & Women $(n=60)$ & $\operatorname{Men}(n=60)$ & \\
\hline Age (yrs) & $50.12 \pm 4.09$ & $49.72 \pm 3.91$ & 0.749 \\
\hline $\mathrm{BW}(\mathrm{kg})$ & $73.43 \pm 12.71$ & $81.25 \pm 13.26$ & 0.001 \\
\hline $\mathrm{BH}(\mathrm{cm})$ & $165.33 \pm 5.50$ & $172.4 \pm 7.00$ & 0.000 \\
\hline $\mathrm{BMI}\left(\mathrm{kg} / \mathrm{m}^{2}\right)$ & $27.41 \pm 4.17$ & $28.11 \pm 4.44$ & 0.314 \\
\hline D.M.d (yrs) & $2.78 \pm 1.29$ & $3.21 \pm 1.45$ & 0.108 \\
\hline $\mathrm{SBP}(\mathrm{mmHg})$ & $116.38 \pm 8.58$ & $113.10 \pm 7.11$ & 0.297 \\
\hline $\mathrm{DBP}(\mathrm{mmHg})$ & $79.58 \pm 3.24$ & $78.62 \pm 2.56$ & 0.088 \\
\hline Glic (mmol/l) & $5.94 \pm 0.29$ & $5.93 \pm 0.37$ & 0.933 \\
\hline Urea $(\mathrm{mmol} / \mathrm{l})$ & $7.41 \pm 0.60$ & $7.31 \pm 0.65$ & 0.453 \\
\hline Cre $(\mathrm{mmol} / \mathrm{l})$ & $81.02 \pm 7.02$ & $79.41 \pm 7.98$ & 0.242 \\
\hline Chol-tot $(\mathrm{mmol} / \mathrm{l})$ & $6.00 \pm 0.52$ & $5.86 \pm 0.60$ & 0.112 \\
\hline $\operatorname{LDLchol}(\mathrm{mmol} / \mathrm{l})$ & $3.51 \pm 0.58$ & $3.52 \pm 0.41$ & 0.546 \\
\hline HDL-chol (mmol//) & $0.99 \pm 0.29$ & $1.02 \pm 0.07$ & 0.265 \\
\hline Trig (mmol/l) & $2.16 \pm 0.22$ & $2.15 \pm 0.25$ & 0.329 \\
\hline
\end{tabular}

Values are mean $\pm \mathrm{SD}$. BW = body weight; $\mathrm{BH}=$ body height; $\mathrm{BMI}=$ body mass index; $\mathrm{D} . \mathrm{M} . \mathrm{d}=$ diabetes mellitus duration; $\mathrm{SPB}=$ systolic blood pressure; $\mathrm{DPB}=$ diastolic blood pressure; $\mathrm{Glic}=$ glicemia; $\mathrm{Kre}=$ creatinin; $\mathrm{Chol}$-tot = total holesterol; $\mathrm{LDL}$-chol = low density holesterol; $\mathrm{HDL}$-chol glicemia; Kre=creatinin; Chol-tot $=$ total holes
$=$ hight density holesterol; Trig $=$ trigicerides. 
Analyzed clinical, laboratoric and echocardiographic characteristics in relation to SEX, in dibetic group, are given in the following tables (Tables 3 , 4). There were not significant differences of, influence of the SEX, in clinical and laboratoric characteristics (Table 3). Also, there were not significant influence of the SEX, in echocardiographic characteristics in dibetic group $\mathrm{p}>0.05$ $(p=0.35)$ (Table 4).

Table 4: Analyzed echocardiographic characteristics in relation to sex in diabetic group.

\begin{tabular}{|c|c|c|c|}
\hline \multicolumn{4}{|c|}{ DM Group $(n=120)$} \\
\hline Variables & Women $(n=60))$ & $\operatorname{Men}(n=60)$ & p Value \\
\hline $\mathrm{LA}(\mathrm{cm})$ & $3.48 \pm 0.43$ & $3.48 \pm 0.45$ & 0.682 \\
\hline ILA (cm/sf.t) & $0.06 \pm 0.01$ & $0.05 \pm 0.01$ & 0.778 \\
\hline Ao $(\mathrm{cm})$ & $3.12 \pm 0.39$ & $3.44 \pm 0.38$ & 0.000019 \\
\hline LVED-d $(\mathrm{cm})$ & $4.67 \pm 0.56$ & $5.05 \pm 0.41$ & 0.000057 \\
\hline LVES-d (cm) & $2.86 \pm 0.32$ & $3.09 \pm 0.28$ & 0.000027 \\
\hline THPW $(\mathrm{cm})$ & $1.12 \pm 0.13$ & $1.14 \pm 0.14$ & 0.432 \\
\hline THS $(\mathrm{cm})$ & $1.00 \pm 0.12$ & $1.01 \pm 0.13$ & 0.807 \\
\hline $\mathrm{EF}(\%)$ & $0.67 \pm 0.06$ & $0.68 \pm 0.06$ & 0.524 \\
\hline SHF (\%) & $0.37 \pm 0.04$ & $0.38 \pm 0.05$ & 0.571 \\
\hline $\mathrm{E}(\mathrm{cm})$ & $0.63 \pm 0.16$ & $0.67 \pm 0.16$ & 0.352 \\
\hline$A(\mathrm{~cm})$ & $0.56 \pm 0.12$ & $0.55 \pm 0.13$ & 0.809 \\
\hline $\mathrm{E} / \mathrm{A}(\mathrm{cm})$ & $1.13 \pm 0.44$ & $1.22 \pm 0.51$ & 0.481 \\
\hline$E / A>1.0 \mathrm{n}(\%)$ & $35(58.3 \%)$ & $40(66.6 \%)$ & NS \\
\hline$E / A<1.0 n(\%)$ & $25(41.6 \%)$ & $20(33.3 \%)$ & 0.350 \\
\hline DC-t E (msec) & & $258.03 \pm 45.45$ & 0.011934 \\
\hline IVR-t (msec) & $97.40 \pm 13.47$ & $98.88 \pm 16.06$ & 0.359 \\
\hline LVM (gr) & $109.14 \pm 24.50$ & $119.48 \pm 23.00$ & 0.011 \\
\hline ILMVM $\left(\mathrm{gr} / \mathrm{m}^{2}\right)$ & $59.88 \pm 13.47$ & $60.32 \pm 11.66$ & 0.401 \\
\hline
\end{tabular}

Values are mean $\pm \mathrm{SD}$ or $\mathrm{n}(\%)$. LA =levt atrium; ILA = indexed left atrium; $\mathrm{Ao}=$ aortae; $\mathrm{ED}-\mathrm{d}=\mathrm{end}$ diastolic dimension of left ventricle; ES- $d$ = end systolic dimension of left ventricle; THPW = thickening of posterior wall; THS = thickening of septum; EF = ejection fraction; FS = fraction of shortening; $L \mathrm{VVM}=$ left ventricular mass; ILVM =indexed left ventricular mass; $E=$ peac velosity of $\mathrm{E}$-wave; $\mathrm{A}$ = peac velosity of $\mathrm{A}$-wave; IVRT = isovolumetric relaksation time; $\mathrm{DC}$-tE= deceleration time of E-wave.

Logistic Regresion model were used to identify association of subclinical levt ventricular diastolic disfunction and clinical,laboratoric and echocardiographic characteristics.All parameters are given in following tables (Tables 5-7). There is a significant association between the subclinical left ventricular diastolic dysfunction of the levt ventriculi and Diabetes Mellitus [(Chi Square $=12.87$ and $p<0.01(p=0.002)]$. The patient from type 2 diabetes group, for [O.R. $=3.97(95 \% \mathrm{Cl} 1.73-9.11)]$ have 3.97 times, higher risk for subclinical left ventricular diastolic dysfunction, rather than the patient from the control group. The women for [O.R. $=1.21(95 \% \mathrm{Cl} 0.63-2.36)]$ have 1.21 times greater but not significant risk than the men,for subclinical left ventricular diastolic dysfunction (Table 5). There is a significant association between the

Table 5: The results of logistic regression of association of diabetes and gender, as independent parameters and left ventricular diastolic disfunction as dependent parameter.

\begin{tabular}{|c|c|c|c|c|c|c|c|c|c|}
\hline & & \multirow{2}{*}{ B } & \multirow{2}{*}{ S.E. } & \multirow{2}{*}{ Wald } & \multirow{2}{*}{ df } & \multirow{2}{*}{ Significance } & \multirow{2}{*}{$\operatorname{Exp}(B)$} & \multicolumn{2}{|c|}{$95.0 \%$ C.I.for $\operatorname{Exp}(B)$} \\
\hline & & & & & & & & Lower & Upper \\
\hline \multirow{3}{*}{ Step 1 (a) } & Gen. (1) & .194 & .339 & .326 & 1 & .568 & 1.214 & .625 & 2.359 \\
\hline & DM.gr (1) & 1.378 & .425 & 10.525 & 1 & .001 & 3.965 & 1.725 & 9.113 \\
\hline & Constant & -1.972 & .421 & 21.931 & 1 & .000 & .139 & & \\
\hline
\end{tabular}

Variable(s) entered on step 1(a): gen (1) = femail; group (1) D.M. subclinical left ventricular diastolic dysfunction as dependent variable and:age, BMI, Tot-chol, LDL-chol,and trygliceride as independent variables [(ChiSquare $=38.23$ and $p<0.001$ $(p=0.000)]$.

Table 6: The results of logistic regression of assotiation of clinical, laboratory characteristics and levt ventricular diastolic disfunction.

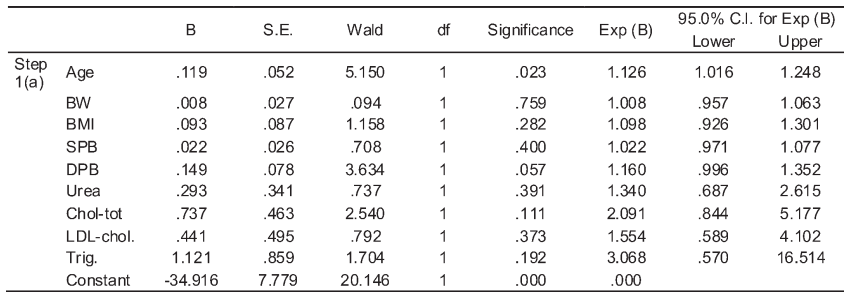

$\mathrm{BW}=$ body weight; $\mathrm{BMI}=$ body mass index $; \mathrm{SPB}=$ systolic blood pressure $; \mathrm{DPB}=$ diastolic blood pressure; $\mathrm{Chol}$-tot $=$ total holesterol; $\mathrm{LDL}$-chol $=$ low density holesterol; Trig = trigicerides.

The biggest significance in the tested model has the age $($ Wald $=5.15)$ and $p<0.05(p=0.02)$. The age, for $[O . R .=1.126(95 \% \mathrm{Cl} 1.02-1.25)]$ has significantinfluence of the subclinical left ventricular diastolic dysfunction. Namely, with the showing of the age for 1 year, the subclinical left ventricular diastolic dysfunction of the heart increases by $12.6 \%$ (Table 6). There is significant assotiation between the subclinical left ventricular diastolic dysfunction as an addictive occurrence and the Echocardiographic parameters as independent variables $[($ Chi Square $=148.18)$ and $p<0.001(p=0.000)]$. The greatest significance in the tested model has E/A relation (Wald $=35.12)$ whose is $p<0.001(p=0.000)$, then on IVR$\mathrm{t}[($ Wald $=4.35) \mathrm{p}<0.05(\mathrm{p}=0.04)]$. From the $\operatorname{Exp}(\mathrm{B})$ values

Table 7: The results of logistic regression of association of echocardiographic characteristics and left ventriculary diastolic disfunction.

\begin{tabular}{|c|c|c|c|c|c|c|c|c|c|}
\hline & \multirow[t]{2}{*}{ B } & \multirow[t]{2}{*}{ S.E. } & \multirow[t]{2}{*}{ Wald } & \multirow[t]{2}{*}{ df } & \multirow[t]{2}{*}{ Sig. } & \multirow[t]{2}{*}{$\operatorname{Exp}(B)$} & \multicolumn{2}{|c|}{$95.0 \%$ C.I.for $\operatorname{Exp}(\mathrm{B})$} \\
\hline & & & & & & & & Lower & \\
\hline \multirow{8}{*}{$\begin{array}{l}\text { Step } \\
1 \text { (a) }\end{array}$} & Ao & -.510 & .846 & .363 & 1 & .547 & .601 & .114 & 3.155 \\
\hline & THPW & 3.721 & 2.981 & 1.558 & 1 & .212 & 41.298 & 120 & 14229.851 \\
\hline & THS & 1.175 & 3.237 & . 132 & 1 & .717 & 3.239 & .006 & 1844.681 \\
\hline & $E / A$ & -6.746 & 1.138 & 35.117 & 1 & .000 & .001 & .000 & .011 \\
\hline & DC-t E & .006 & .007 & .641 & 1 & .423 & 1.006 & .992 & 1.020 \\
\hline & IVR-t & .052 & .025 & 4.350 & 1 & 037 & 1.053 & 1.003 & 1.106 \\
\hline & ILMVM & .002 & .016 & .017 & 1 & .896 & 1.002 & .970 & 1.035 \\
\hline & Constant & -4.155 & 4.872 & .727 & 1 & .394 & .016 & & \\
\hline
\end{tabular}

$\mathrm{Ao}=$ aortae$; \mathrm{THPW}=$ thickening of posterior wall; $\mathrm{THS}=$ thickening of septum; $\mathrm{DCtE}=$ deceleration time of $\mathrm{E}$-wave; ILVM = indexed left ventricular mass.

that give the priority relation the following is observed: The E/A relation $<1.0$ for [(O.R. $=0.001(95 \% \mathrm{Cl} 0.00-0.01)]$ there is a significant association between the subclinical left ventricular diastolic dysfunction as an addictive occurrence and the Echocardiographic parameter as independent variables. 
The Duration of the isovolumenic relaxation for $[(O . R .=1.053(95 \% \mathrm{Cl} 1.003-1.106)]$ there is a significant assotiation between the the subclinical left ventricular diastolic dysfunction as an addictive occurrence and the Echocardiographic parameter as independent variables (Table 7).

\section{Discussion}

Clinical left ventricular diastolic dysfunction is associated to diabetes and in absence of other predisposed factors, is defined as a diabetic cardiomiopathy, with the most prominent histological changes: myocelular hypertrophy and myocardial fibrosis, implicating functional and structural changes in the myocardium [2-5].

Clinical data for the involvement of the left ventricle at the patient with type 2 diabetes, including the diastolic dysfunction, are noticed [1]. The profile of the ventricle filling at the patient with type 2 diabetes, is frequently abnormal, reflecting the basic abnormalities of relaxation and/or reduced myocardial compliance. The left ventricular diastolic dysfunction is proven with: prolonging the isovolumenic relaxation, the speeded up filling of the left ventricle, and the reduction of early diastolic filling [6-12]. The compliance is general, that, the diastolic dysfunction at the patient with type 2 diabetes, can be detected early in the course of the disease, before that the systolic dysfunction [30].

The echocardiographyexamination provides easy detection of the beginning abnormalities of the leftventricular diastolic dysfunction before the clinical appearance. The Doppler echocardiography is generally accepted noninvasive method for studying the left ventricular diastoic disfunction. In our study, we used the Doppler echocardiography for estimation of: the influence of type 2 diabetes over the occurrence of the subclinical left ventricular diastolic dysfunction though analysis of the transmitral flow-velocity, with pulsed-wave doppler, at patient with type 2 diabetes. This study provides solid evidence for the existing of the association between diabetes and diastolic dysfunction and in the absence of coronary disease, high blood pressure disease, hypertrophy of the myocard and other well known heart diseases.

Our results showed significant difference of the doppler parameter of diastoic function between the patients with type 2 diabetis and the control group. The acquired results point out that at the patient with type 2 diabetis there is a pathological trnasmitral flow-velocity profile, or, a characteristic model of delayed (late) relaxation, reduced speed of transmitral flow in the phase of early ventricular filling (E-wave), decreased E/A relation $<1.0$ and prolongation of the isovolumenic relaxation time $(>100 \mathrm{mil} /$ s). This model of transmitral flow, points out to the extistance of left ventricular diastoic disease at theese sick. The results of scientific studies so far, in connection with the distribution of fucntional abnormalities (the sistolic and diastolic disfunction) at the asimtomatically patient with type 2 diabetis are unclear [2, 45, 60-68].

In the study of Cosson S, at the patient with type 2 diabetis, the subclinical left ventricular diastoic disfunction was not proven [65]. In the study of Fang ZY, the distribution of subclinical left ventricular diastolic dysfunction at the patient with type 2 diabetes is noted at $27 \%$ [2]. In the Stephanie K study, the subclinical left ventricular diastolic dysfunction at the patient with type 2 diabetes is noted at 48\% [45]. In Boyer JK's study, the distribution of subclinical left ventricular diastolic dysfunction at the patient with type 2 diabetes is noted at $75 \%$ [66]. In our study the distribution of subclinical left ventricular diastolic dysfunction at the patient with type 2 diabetes is noted at $37.5 \%$ of the patient with type 2 diabetes. In our study the diastolic abnormalities are proven at the patient with type 2 diabetes and in absence of coronary disease, high blood pressure disease, hypertrophy of the myocardium and other well known heart diseases. Results that are similar to previous studies for the diabetic heart disease (diabetic cardiomiopathy) described at the patient with type 2 diabetes in the absence of coronary disease, high blood pressure disease, and other well known heart diseases $[3$, 5].

The results of our study proved that subclinical left ventricular diastolic dysfunction at the patient with type 2 diabetes shown by the model of impaired relaxation (pathological model) of ventriclular filling, that points out to the diastolic dysfunction of the $1^{\text {st }}$ degree, occurs in the early stages of the diabetic heart disease. The results of our study are similar to those of the Di Bonito et al study, in which the diastolic abnormalities were noted in the early stages of the diabetic heart disease at the asymptomatic patient with diabetes [4].The reduction of the systolic function of the left ventricle is proven in many studies at the asymptomatic patient with type 2 diabetis. The chronic abnormalities of the carbohydrates in the myocardiocites, abnormalities of the metabolism of fats at the patient with diabetes, results in the reduction of activity of adenosine trifosfatasis, reduction of the capability of sarkoplasmatic reticulum for the calcium and the accumulation of intermediate toxic fat acids, and with that a reduction of 
the sistolic function [1].

In the Vanninen study a reduced ejectional fraction at the asymptomatically patient with type 2 diabetes has been proven [68]. Even besides thatin many epidemiological observations, the increased frequency of heart failure at the patient with diabetes has been proven, they have demonstrated normal systolic function on the left ventricle in a calm state. In the Mustonen JN study, a significant difference was not proven of the ejectional fraction between the patient with type 2 diabetes and the control group [60]. In our study the difference in the ejectional fraction between the compared groups is not mentioned.

At these situations, the changes in the state of calm may be too subtle to be identified through indicators to be load-dependent, as the ejectional fraction of the left ventricle, and according to that, an application of more sensitive techniques is necessary $[60,68]$. The abnormal relaxation of the left ventricle, present at the patient with diabetes (the reduction of values of the E/A relation) is assotiated to the increased morbidity of the patient with diabetes and can contribute in the incensement of the incidence of the congestive heart failure, and if it does, the normal ejectional fraction of the left ventricle [3]. Significant interaction between diabetes and the sex is found in many studies [61-63]. The difference in sex in the prevalence of cardiovascular disease is observed clinically and experimented [63].

In the Ida G study, it is proven that women with diabetes have a higher relative risk of cardiovascular diseases that with men with diabetes, in comparison to the men and women without diabetes [63]. The explanation for this greater risk at women remains unclear. In the Fand Zy study, the influence of sex in the distribution of subclinical left ventricular diastolic dysfunction at the ones with type 2 diabetes is not proven [2]. Also, the Bajraktari $G$ study does not prove the influence of sex in the distribution of subclinical left ventricular diastolic dysfunction at the ones with type 2 diabetes [59]. In both studies it is mentioned that as a limitation of the studies the small number of women included in the studies. In Suys BE study, it is proven that the changes in the diastolic function and dimension of the left ventricle at women with type 2 diabetes are more significant [62].

In our study we do not prove significant influence of the sex in the distribution of subclinical left ventricular diastolic dysfunction nor in the dimensions of the left ventricle at the patient with type 2 diabetes. But, the results from the logistic regresional analysis show that women with type 2 diabetes have 1.21 times greater risk of development of subclinical diastolic dysfunction, in relation to men. A result that shows that with examination of the subclinical left ventricular diastolic dysfunction in the larger examined group with patient with type 2 debates, maybe it can be proven that the right influence of the sex in the distribution of the subclinical left ventricular diastolic dysfunction at the patient with type 2 diabetes. The received results in our study did not prove the given hypothesis that the potential for type 2 diabetes in the precipitation of subclinical left ventricular diastolic dysfunction atwomen, in the absence of coronary disease, high blood pressure disease and other well known heart diseases, is different in comparison to males. The results of examinations so far regarding the influence of duration of diabetes in left ventricular diastolic dysfunction are unclear.

In Jenifer EL study it is proven that a positive correlation between the duration of diabetes and the distribution of left ventricular diastolic dysfunction [36]. The connectedness between the duration of diabetes and the functional, structural changes of the left ventricle are proven in many clinical studies, but not in all studies [6264]. In the Suyis BE study, the weak-positive correlation between the duration of diabetes and the left ventricular diastolic dysfunction is proven [62]. Fiorini G, in his study did not prove the correlation between the duration of diabetes and the indicators of diastolic function of the left ventricle. In the same study the correlation between age and E/A relation was also not proven nor the correlation between the systolic function and duration of diabetes [64]. In the Fang ZY study, the correlation between the duration of diabetes and the diastolic abnormalities, the left ventricular diastolic and systolic dysfunctions are not proven [2]. And also in the Fiorini $G$ study the connectedness between the duration of diabetes and the decreased left ventricular diastolic and systolic dysfunctions at the patient with type 2 diabetes are not proven [69].

In our study we do not prove an influence of the duration of type 2 diabetes in: the distribution of the subclinical left ventricular diastolic dysfunction, nor in the structural and functional changes of the myocardium at the patient with type 2 diabetes. The connectedness between the left ventricular diastolic dysfunction and the age of the patient with type 2 diabetes is proven in most studies [2, 5, 19]. Fang ZY in his study, it is proven that there is significant connectedness between the left ventricular diastolic dysfunction and the age of the patient with type 2 diabetes. The study proves the positive correlation between the age of people tested with diabetes 
and the E/A relation, the duration of the deceleration of the $\mathrm{E}$-wave, and the duration of the isovolumenic relaxation [2]. In the Tokushima T study, a significant connectedness between the age and the diastolic abnormalities of the left ventricle is proven. The age is connected with the decrease of the top velocity of the E-wave, the increase of the top velocity of the A-wave and the increased duration of the isovolumenic relaxation [19].

The results of our study proved a significant connectedness between the subclinical left ventricular diastolic dysfunction and the age of the patient with type 2 diabetes, results similar to other studies $[2,5,19]$. The connectedness between left ventricular diastolic dysfunction at the patient with type 2 diabetes and the body mass index, is proven in clinical and experimental studies [10, 59]. The results of our study proved that the body mass index at the patient with type 2 diabetis and the subclinical left ventrucular diastolic disfunction is greater in relation to the body mass index at the patient with type 2 diabetes, with normal left ventrucular diastoic disfunction. Results that is similar in other studies $[10,59,67]$.

In animal and clinical studies, the correlation between the left ventricular diastolic dysfunction and the level of fat in the blood is proven. With the increase of the fat levels in blood, their accumulation in the myocardiocites increases, this results in lipotoxical damages of the myocardium (mitochondrial dysfunction, oxygen-giving products, and inflammatory cascade apoptosis) and development of diabetic cardiomyopathy. Accumulation of triglycerides in the myocardium at the people sick with type 2 diabetes results in left ventricular diastolic dysfunction regardless of age, body mass index, blood pressure and heart frequency [70]. The increased accumulation of triglycerides in the myocardium is seen early in the natural history of type 2 diabetes. Luuk JR in his study proved the positive association between the incensement of the level of triglycerides in the blood at the patient with type 2 diabetes, with the increase of content of triglycerides in the myocardium and diastolic dysfunction [70]. In the same study, the inverse correlation between the incensement of the level of HDL-cholesterol in the blood with diastolic dysfunction is proven, regardless of age, body mass index, obesity, heart frequency and diastolic blood pressure. In the Vinereanu D study, the negative correlation between the level of LDL-cholesterol and the systolic function at the patient with type 2 diabetes is proven[71].

In our study, the level of triglycerides in the blood at the patient with type 2 diabetes and the left ventricular diastolic dysfunction was significantly higher in comparison with the normal diastolic function at the patient with type 2 diabetes. In our study the level of LDL-cholesterol was significantly higher at the patient with type 2 diabetes and the patient with diastolic dysfunction, in comparison to the patient with type 2 diabetes with normal diastolic function. The results are similar in newer publications $[70,71]$. On the basis of the results from the cited studies, and from the results of our study, we can set the hypothesis that the course of the diabetic heart disease begins with an accumulation of the fats in the myocardiocities, belonging previously to the diastolic dysfunction.

Limitations of the examination: At the patient that were included in our study, coronary arteriography, for exclusion of coronary disease as a reason for the left ventricular diastolic dysfunction, was not performed because it is difficult to influence the patient asymptomatically, for an invasive procedure, and also from an ethical stand point. This limitation is unavoidable. We carefully included only the patient with type 2 diabetes in our study without clinical, electrocardiographic sings for coronary disease, as well as signs of regional abnormalities in the echocardiogram. But, the latent subclinical coronary arteriosclerosis cannot be wholly disregarded. We do not believe that the subtle coronary arteriosclerosis would have an influence in the received results at a significant degree. Also in our study we did not register the pulnomal vein flow for getting comparable parameters for the left ventricular diastolic dysfunction. We believe that these limitations will not reduce the values of the basic conclusions of the study.

Conclusions: 1). The subclinical left ventricular diastolic dysfunction is common at the patient with type 2 diabetes in comparison to those without diabetes, for the same age and sex. 2).The subclinical left ventricular diastolic dysfunction is common at the patient with type 2 diabetes and in absence of coronary disease; high blood pressure disease and other well know heart diseases. 3. In this study, we did not prove the hypothesis that: the potential of type 2 diabetes, in precipitation of the subclinical left ventricular diastolic dysfunction at females in absence of coronary disease, high blood pressure disease and other well know heart diseases, differs, in comparison with males. 4). Doppler-choreography is notan invasive method, is widely accepted, for the early discovery of one subclinical risky marker, as is the subclinical left ventricular diastolic dysfunction at the patient with diabetes. 5). The common appearance of left ventricular diastolic dysfunction at the patient with type 2 diabetes, as suggested in our study as well, supports the use of echocardiography, in the first clinical evaluation of the patient with type 2 diabetes. 
6).Early discovery of myocardial manifestation of the diabetes melit is of significant importance, because the inclusion of the miocard, significantly influences the progosis of the patient with diabetic melit. 7) The early discovery of subclinical left ventricular diastolic dysfunction as well as the early inclusion of medical treatment with bblockators and ace-inhibitors, we can successfully do, a primary intervention of the clinically manifested heart disease, which is also a recommendation of the American and European Cardiologic Associations [78]. With the interventions for reducing the level of fat at the asymptomatically patient with type 2 diabetes and diastolic dysfunction, we can successfully do a primary prevention of a clinical manifestation of heart failure.

From the abovementioned conclusions we can say that: At the patient with type 2 diabetes, functional problems (subclinical left ventrucular diastoic disfunction) in the miocard are present before the development of miocardial sistolic disfunction. These changes potentially belong to the consecutive development of the manifested diabetic cardiomyopathy.

\section{References}

1.Kannel WB,McGee DL. Diabetets and cardiovardiovascular risk factors: the Framingham study. Circulation. 1979;59:813.

2.Fang ZY,Johanes P,Marwick TH. Diabetic Cardiomyopathy: Evidence, Mekanisms, and therapeutic implication.Endocrine Riews. 2004;25(4):543-67.

3.Marwick TH. Diabetic Heart Disease. Heart. 2006;92:296300.

4.Di Bonito P,Cuomo S,Moio N,et al. Diastolic Disfunction in patient with non insulin-dependent diabetes mellitus of short duration. Diabet Med.1996;13:321-4.

5. Inoue T, Fujito T, Asahi S, et al. Impaered of levt ventriculary diastolic filing occur in diabetic patient without atherosclerotic coronary artery disease. Am J Med Sci.1997;313:125-30.

6. Cerutti F, Vigo A, Sacchetti C, Bessone A, Barattia G, Morello M, Casalucci D, Gastaldi L. Evaluation of left ventricular diastolic function in insulin dependent diabetic children by M-mode and Doppler echocardiography. Panminerva Med. 1994;36(3):109-14.

7. Rajan SK, Gokhale SM. Cardiovaskular function in patient with insulin-dipiendent diabetes mellitus: a stady using noninvasive methods. Ann NY Acad Sci. 2002;958:425-30.

8. Semeniuk LK, Kryski AJ, Severson DL. Echocardiographic assessment of cardiac fungtion in diabetic $\mathrm{db} / \mathrm{dp}$ and ransgenic db/db-hGLUT4 mice. Am J Physiol Heart Circ
Physiol. 2002.283:H976-H982.

9. Ganguly PK, Thliversis JA, Mehta A. Evidence against the involvement of nonenzymatic glycosylation in diabetic cardiomyopethy. Metabolism. 1990;39:769-73.

10. Shimizu M, Sugihara N, Kita Y, Shimizu K, Shibayama S, Takeda R. Increase in left ventricular chamber stiffness in patients with non-insulin dependent diabetes mellitus. Jpn Circ J. 1991; 55:657-664.

11. Bouchard A, Sanz N, Botvinick EH, et al. Noninvasive assessment of cardiomyopathy in normotensive diabetic patients between 20 and 50 years old. AmJ Med. 1989;87:160-66.

12. Airaksinen J, Ikaheimo M, Kaila J, et al. Impaired left ventricular filling in young female diabetics. An echocardiographic study. Acta Med Scand. 1984; 216: 509516.

13. Strauer BE, Motz W, Vogt M, et al. Impaired coronary flow reserve in NIDDM: a possible role for diabetic cardiopathy in humans. Diabetes. 1997; 46(Suppl 2):S119S1247.

14. Poirier P, Bogaty P, Garneau C, et al. Diastolic dysfunction in normotensive men with well-controlled type 2 diabetes: importance of maneuvers in echocardiographic screening for preclinical diabetic cardiomyopathy. Diabetes Care. 2001; 24:5-10.

15. Schannwell CM, Schneppenheim M, Perings S, Plehn G, et al. Left ventricular diastolic dysfunction as an early manifestation of diabetic cardiomyopathy. Cardiology. 2002; 98: 33-39.

16. Paillole C, Dahan M, Paycha F, et al. Prevalence and significance of left ventricular filling abnormalities determined by Doppler echocardiography in young type I (insulindependent) diabetic patients. Am J Cardiol. 1998;64:10101016.

17. Zabalgoitia M, Ismaeil MF, Anderson L, et al. Prevalence of diastolic disfunction in normotenzive, asymptomatic patient with well-controlled type-2 diabetes mellitus. Am J Cardiol. 2001;87:320-3.

18. Shehadeh A, Regan TJ. Cardiac consequences of diabetes mellitus. Clin Cardiol. 1995;18:301-305.

19. Tokushima T, Reid CL, Gardin JM. Levt ventricular diastolic function in the elderly. Am J Geriatr Cardiol. 2001;10(1):20-9.

20. Mathew P, John L, Jose J, Krishnaswami S. Assessment of left ventricular diastolic function in young diabetics- a two dimensional echo Doppler study. Indian Heart J. 1992;44:29-32.

21. Mottrm Ph, Marwick. Assesment of diastolic function: what the general cardiologist need to know. Heart. 2005;91:681695. 
Jani \& Spiroska. Type 2 Diabetes and the Sex on Sub-Clinic Left-Ventricular Diastolic Dysfunction

22. Joffe II, Travers KE, Perreault-Micale CL, et al. Abnormal cardiac function in the streptozotocin-induced non-insulindependent diabetic rat: noninvasive assessment with Doppler echocardiography and contribution of the nitric oxide pathway. J Am Coll Cardiol. 199;34:2111-2119.

23. Wold LE, Relling DP, Colligan PB et al. Characterization of contractile function in diabetic hypertensive cardiomyopathy in adult rat ventricular myocytes. J Mol Cell Cardiol. 2001;33:1719-1726.

24. Hoit BD, Castro C, Bultron G, et al. Noninvasive evaluation of cardiac dysfunction by echocardiography in streptozotocininduced diabetic rats. J Card Fail.1999; 5:324-333.

25. Friedman NE, Levitsky LL, Edidin DV, et al. Echocardiographic evidence for impaired myocardial performance in children with type I diabetes mellitus. Am J Med. 1982;846-50.

26. Mbanya JC, Sobngwi E, Mbanya DS, et al. Left ventricular mass and systolic function in African diabetic patients: association with microalbuminuria. Diabetes Metab. 2001; 27:378-382.

27. Fang ZY, Yuda S, Anderson V, et al. Echocardiographic detection of early diabetic myocardial disease. J Am Coll Cardiol. 2003;41:611-617.

28. Scognamiglio R, Casara D, Avogaro A. Myocardial dysfunction and adrenergic innervation in patients with type 1 diabetes mellitus. Diabetes Nutr Metab. 2000;13:346-349.

29. Baum VC, Levitsky LL, Englander RM. Abnormal cardiac function after exercise in insulin-dependent diabetic children and adolescents. Diabetes Care. 1987;10:319-323.

30. Vered A, Battler A, Segal P, et al. Exercise-induced left ventricular dysfunction in young men with asymptomatic diabetes mellitus (diabetic cardiomyopathy). Am J Cardiol. 1984;54:633-637.

31. Carlstrom S, Karlefors T. Haemodynamic studies on newly diagnosed diabetics before and after adequate insulin treatment. Br Heart J. 1970;32:355-358.

32. Karlefors T. Haemodynamic studies in male diabetics. Acta Med Scand. 1966;449:45-80.

33. Nugent AM, Steele IC, al Modaris F, et al. Exercise responses in patients with IDDM. Diabetes Care. 1997;20:1814-1821.

34. Fang ZY, Yuda S, Anderson V, et al. Echocardiographic detection of early diabetic myocardial disease. J Am Coll Cardiol. 2003;41:611-617.

35. Thompson EW. Structural manifestations of diabetic cardiomyopathy in the rat andits reversal by insulin treatment. Am J Anat. 1988;182:270-282.

36. Liu JE, Palmieri V, Roman MJ, et al. The impact of diabetes on the levt ventricular filling patern in normotensive and hypertensive adult:the strong heart study. J Am Coll Cardiol. 2001;37:1943-9.

37. Ruter MK, Parisie H, Benjamin EJ, et al. Impact of glucose tolerance and insulin resistance on cardiac structure and function:sex-related differences in the Frmingham heart study. Circulation. 2003;107:448-54.

38. Watts GF, Marwick TH. Ventricular disfunction in early diabetic heart disease:detection, mechanisms and significance. Clin Sci(Lond). 2003;105:537-40.

39. Frustaci A, Kajstura J, Chimenti C, et al. Myocardial cell death in human diabetes. Circ Res. 2000;87:1123-11326.

40. Cai L, Li W, Wang G, et al. Hyperglycemia-induced apoptosis in mouse myocardium: mitochondrial cytochrome C-mediated caspase-3 activation pathway. Diabetes. 2002; 51:1938-1948.

41. Sonnenblick EH, Fein F, Capasso JM, et al. Microvascular spasm as a cause of cardiomyopathies and the calcium-blocking agent verapamil as potential primary therapy. Am J Cardiol. 1985;55:179B-184B.

42. Nakano S, Kitazawa M, Ito T, et al. Insulin resistant state in type 2 diabetes is related to advanced autonomic neuropathy. Clin Exp Hypertens. 2003;25:155-167.

43. Factor SM, Minase T, Cho S, et al. Coronary microvascular abnormalities in the hypertensive-diabetic rat. A primary cause of cardiomyopathy? Am J Pathol. 1984;116:9-20.

44. Blumenthal HT, Alex M, Goldenberg S. A study of lesions of the intramural coronary branches in diabetes mellitus. Arch Pathol. 1960;70:27-42.

45. Stephanije KI, Rolf HA, Ruth JM, et al. Pre-clinical diabetic cardiomyopathy: Prevalence, screening, and outcome. Eur J Heart Failure. 2010;12:951-57.

46. Sunni S, Bishop SP, Kent SP, et al. Diabetic cardiomyopathy. A morphological study of intramyocardial arteries. Arch Pathol Lab Med. 1986;110:375-381.

47. Sutherland CG, Fisher BM, Frier BM, et al. Endomyocardial biopsy pathology in insulin-dependent diabetic patients with abnormal ventricular function. Histopathology. 1989;14:593602.

48. Strauer BE, Motz W, Vogt M, et al. Impaired coronary flow reserve in NIDDM: a possible role for diabetic cardiopathy in humans. Diabetes. 1997;46(Suppl 2):S119-S.

49. Pitkanen OP, Nuutila P, Raitakari OT. Coronary flow reserve is reduced in young men with IDDM. Diabetes. 1998;47:248254.

50. Yokoyama I, Ohtake T, Momomura S, et al. Hyperglycemia rather than insulin resistance is related to reduced coronary flow reserve in NIDDM. Diabetes. 1998;47:119-124.

51.Ganguly PK, Pierce GN, Dhalla KS, et al. Defective 
sarcoplasmic reticular calcium transport in diabetic cardiomyopathy. Am J Physiol. 1983;244:E528-E535.

52. Calles-Escandon J, Cipolla M. Diabetes and endothelial dysfunction: a clinical perspective. Endocr Rev. 2001;22:3652.

53. Pitkanen OP, Nuutila P, Raitakari OT, et al. Coronary flow reserve is reduced in young men with IDDM. Diabetes. 1998;47:248-2545.

54. Taylor PD, Graves JE, Poston L. Selective impairment of acetylcholine-mediated endothelium-dependent relaxation in isolated resistance arteries of the streptozotocin-induced diabetic rat. Clin Sci (Lond). 1995;88:519-524.

55. Koya D, King GL. Protein kinase $C$ activation and the development of diabetic complications. Diabetes. 1998;47:859-866.

56. Turpeinen AK, Vanninen E, Kuikka JT, et al. Demonstration of regional sympathetic denervation of the heart in diabetes. Comparison between patients with NIDDM and IDDM. Diabetes Care. 1996;19:1083-1090.

57. Felten SY, Peterson RG, Shea PA, et al. Effects of streptozotocin diabetes on the noradrenergic innervation of the rat heart: a longitudinal histofluorescence and neurochemical study. Brain Res Bull. 1982;8:593-600.

58. Uekita K, Tobise K, Onodera S. Enhancement of the cardiac $ß$-adrenergic system at an early diabetic state in spontaneously diabetic Chinese hamsters. Jpn Circ J. 1997;61:64-73.

59. Bajraktari G, Qirko S, Rexhepaj N, Bakalli A, Beqiri A, Elezi S, Ndrepepa G. Non-insulin dependent diabetes as an independent predictor of asymptomatic left ventricular diastolic dysfunction. Croat Med J. 2005;46(2):225-31.

60. Mustonen JN, Uusitupa MI, Laakso M, et al. Levt ventricular systolic function in mioddle-aged patient with diabet mellitus. Am J Cardiol.1994;73:1202-8.

61. Rejn J, Ceylian-Isik AF. Do women differ from men? Endocrine. 2004;25(2):73-83.

62. Suys BE, Katier N,R, Rooman RP, et al. Female children and adolescents with diabetes mellitus have more pronounced early echocardiographic signs of diabetic cardiomyopathy. Diabetes Care. 2004;27(8):2081-3.

63. Ida G, Bente B, Marie S, et al. Influence of diabetes and diabetes -genger interaction on the risk of death inpatient hospitalized with congestive heart failure. JACC. 2004;43:771-777.

64. Stephanije K, Rolf H, Ruth D, et al. Pre-clinical diabetic cardiomyopathy: Prevalence, screening, and outcome. Eur J Heart. 2010;12:951-57.

65. Cosson S, Kevorkijan JP, Virally ML, et al. No evidence for levt ventricular diastolic disfunktion in asymptomatic normotenzive type-2 diabetic patiets: a case-control study with new echocardiographic techniques. Diabetes Metab. 2007;33(1):61-67.

66. Boyer JK, Thanigaraj S, Schecht KB, et al. Prevalence of ventricular disfunction in asymptomatic, normotesive patient with dibetes mellitus. Am J Cardiol. 2004;93(7):870-5.

67. Redfield MM, Jakobsen SJ, Burnet JC, et al. Burden of systolic and diastolic ventricular dysfunction in the community:appreciating the scope of the heart fealure epidemic. JAMA. 2003;289:194-202.

68. Vanninen E, Mustonen J, Vainio P, et al. Levt ventricular fungction and dimension in newly diagnosed non-insulin dependent diabetes mellitus. Am J Cardiol. 1992;70:371.

69. Fiorini G, Scotti LA, Parmigiani ML, Ferrari M, Pezzoli P, Bignotti G. [An echocardiographic study of left ventricular diastolic function in patients with diabetes mellitus type 2]. G Ital Cardiol. 1995;25(1):17-25.

70. Luuk JR, Rudger VM, Johannes WS et al. Myocardial steatosis is an independent predictor of diastolic disfungcijon in type-2 diabetes mellitus. J Am Coll Cardiol. 2008.52;(22):1793-99.

71. Vinereanu D, Nicolaides E, Tweddel AC, et al. Subclinicl levt ventriculary disfunction in patient with type-2 diabetes mellitus, related to serum lipids and glycated haemoglobin. Clin Sci (Lond). 2003;105(5):537-40.

72. America Diabetes Association. Standards for medical care for patient with diabetes mellitus. Diabetes Care. 2002;25(Suppl 1 0:S33-S49.

73. The Seventh Report of Joint National Committee on PDET of High Blood Preassure. May 2003. NIH Publication No03-5233.

74. Schiller NB, Shah PM, Crawford M, et al. American Society of Echocardiography Committe on standards, subcommittee on Quantifications of Two-Dimensional echocardiograms: Recomandations for quantifications of left ventricle by two- dimensional echocardiography. J Am Soc Echocardiography. 1989;2:258-67.

75. How to diagnose diastolic heart failure. European Study Group on Diastolic Heart Failure. Eur Heart J. 1998;19:9001003.

76. Dewereux R, Alonson DR, Lutas EM. Echocardiographic assessment of levt ventricular hypertrophy: comparison to necropsy findings. Circulation. 1986;57:450-85.

77. Hense HW, Gneiting B, Muscholl M, et al. The associacions the body size and body composition with left ventricular mass: impacts for indexation in adult. J Am Coll Cardiol. 1998;32:451-457.

78. ACC/AHA. Guide line Update.Diagnosis and Management of Chronic Heart Failure in the Adult. J Am Coll Cardiol. 2005;46:1117-39. 